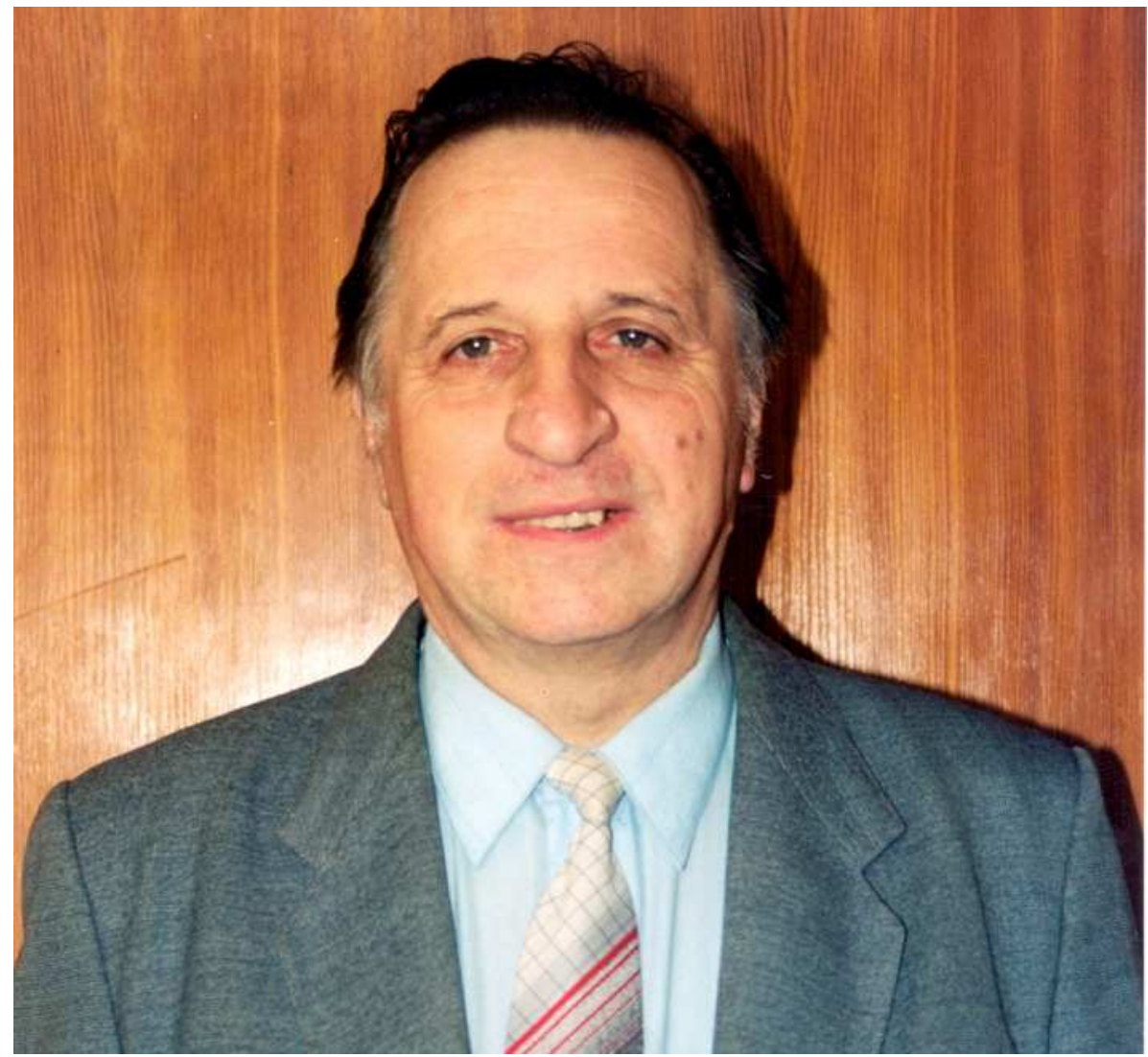

\title{
Professor Roman Levitskii's 60-th anniversary
}

Very soon, in the year at hand, our colleague Professor Roman Levitskii, Head of Department for Model Spin Systems Theory of the Institute for Condensed Matter Physics, member of the Editorial Board of our journal, will celebrate his 60-th birthday. On this occasion, the Editorial board decided to honour him with a collection of papers, related to the problems of ferroelectric crystals, spin systems theory and other fields of condensed matter physics close to Roman Levitskii's scientific interests and written by people who value him as a prominent scientist. Some of the authors had a great pleasure to collaborate with him during many years of his life in science.

Roman Levitskii was born on January 6, 1943 in Cherche, Ivano-Frankivsk region. In 1965 he graduated from the Physics Department of Lviv State University and entered the post-graduate courses at the Department for Solid State Theory of 
this University. His scientific career started in 1969 from the position of a junior research fellow in the Lviv Department of Condensed Matter Statistical Theory of the Institute for Theoretical Physics of Ukrainian Academy of Sciences. His candidate dissertation (1971), completed under the guidance of Prof. I.Stasyuk, was devoted to the problems of a dynamical theory of ferro- and antiferroelectrics with hydrogen bonds. He defended his doctoral dissertation in 1990 and became a professor in 1997.

An important part of the studies performed by Roman Levitskii belongs to a microscopic theory of ferroelectric crystalline and disordered systems with hydrogen bonds. Together with I.Stasyuk and using the pseudospin and pseudospin-phonon models, Roman Levitskii managed to describe a series of peculiarities of thermodynamic and dynamic characteristics of $\mathrm{KH}_{2} \mathrm{PO}_{4}$ type ferroelectrics and antiferroelectrics. On the basis of the proton-phonon model, the properties of the lowfrequency vibrations, including the soft mode, were explored, and the experimentally observed anomalies of elastic neutron scattering were explained. It was shown that the presence of strong short-range correlations in the system leads to renormalization of proton tunnelling as well as to suppression of the soft mode energy. Together with I.Stasyuk and N.Korynevskii he proposed a cluster theory of proton ordering in the hydrogen-bonded systems of orthophosphates $\left(\mathrm{KH}_{2} \mathrm{PO}_{4}\right)$ type, which permitted to consider a mechanism of ferro- and antiferroelectric phase transitions in these crystals from a unified point of view and to calculate their major thermodynamic characteristics. Independently and practically simultaneously with J.Ishibashi there was developed a cluster theory of antiferroelectric phase transitions in $\mathrm{ND}_{4} \mathrm{D}_{2} \mathrm{PO}_{4}$ type antiferroelectrics and for the first time a crucial role of long-range interparticle interactions in establishing the antipolarized state was emphasized.

R.Levitskii's attention was greatly attracted by the studies of relaxational dynamics of hydrogen bonded ferroelectrics, for the description of which, in both ferro(antiferro-)electric and paraelectric phases, he developed a consistent theory based on the Glauber dynamic approach and on the Zubarev non-equilibrium statistical operator techniques. On the basis of the proton ordering model within the proposed scheme, a low-frequency dispersion of dielectric permittivity of the $\mathrm{KH}_{2} \mathrm{PO}_{4}$ and $\mathrm{CsH}_{2} \mathrm{PO}_{4}$ type (including their partially or completely deuterated analogs) was described. Theoretical investigations were carried out in close connection with the experimental studies in this field, performed by J.Grigas and G.Kozlov.

Roman Levitskii's scientific interests of have always varied from describing specific physical systems to developing the abstract mathematical approaches, from investigating complex model systems with different types of interactions to applying the developed techniques and verifying them comparatively with experimental data. Thus, to consistently describe the quantum pseudospin systems having essential short-range and long-range interactions, an approach was required that would permit to use different techniques in order to properly take into account different types of interactions. R.Levitskii together with I.Yukhnovskii and S.Sorokov proposed a method, based on the idea of separating the reference system. This method implies the calculation of the free energy functional with taking into account the short-range interactions within the reference approach (frequently within a cluster 
approximation). The expansions were studied regarding the free energy functional and the functionals of the temperature cumulant Green functions in the inverse long-range interactions radius. For the first time there was proposed a method of calculating the $q$-dependent correlation functions of deuterons in the orthophosphates type systems, using a cluster version of the Ornstein-Zernike type equation. The developed reference approach has been successfully applied to the description of thermodynamic and dynamic properties of hydrogen bonded ferroelectric and antiferroelectric systems having essential short-range and long-range interactions.

The scope of his scientific interests also includes the problems of a statistical description of partially excited molecular systems. Together with I.Yukhnovskii and O.Derzhko, R.Levitskii developed an approach based on virial expansions with separating additional contributions from interparticle resonance interactions, arising at particle transitions to the excited state under the external irradiation. These studies formed a basis for a subsequent description of the gas-liquid phase transitions in these systems.

The most recent interests of Roman Levitskii include theoretical studies of substitutional disorder, tunnelling, external stresses and electric fields effect on the behavior of hydrogen bonded ferroelectrics of the $\mathrm{KH}_{2} \mathrm{PO}_{4}$ family, quasi-one-dimensional systems of the $\mathrm{CsH}_{2} \mathrm{PO}_{4}$ and $\mathrm{PbHPO}_{4}$ type, Rochelle salt, etc, as well as investigations of the role played in these effects by long-range dipole forces and short-range configurational correlations as well as by piezoelectric and electrostrictive interactions. The performed studies yielded a thermodynamically consistent theory that proved a complete suitability of the proton ordering model for the description of thermodynamic, dielectric, piezoelectric, and elastic properties of $\mathrm{KH}_{2} \mathrm{PO}_{4}$ family ferroelectrics.

Roman Levitskii is the author of over 300 scientific papers. Under his guidance 9 researchers have successfully defended their candidate dissertations. For many years Roman Levitskii was a scientific secretary of the Physics Section of the Western-Ukrainian Scientific Center.

The Editorial Board of "Condensed Matter Physics" congratulates Professor Roman Levitskii on the occasion of his anniversary and wishes him vigour as well as long and fruitful life in science. 


\section{Main publications}

1. Stasyuk I.V., Levitskii R.R. On elementary excitations in ferrroelectric with hydrogen bonds. // Ukr. Fiz. Zhurn., 1969, vol. 14, No. 7, p. 1097-1105 (in Russian).

2. Stasyuk I.V., Levitskii R.R. The role of proton-phonon interaction in the phase transition of ferroelectrics with hydrogen bonds. // Phys. Stat. Sol. (b), 1970, vol. 39, No. 1, p. K35-K38.

3. Stasyuk I.V., Levitsky R.R. Coupled vibrations of a proton-ion system in ferroelectrics with hydrogen bonds of $\mathrm{KH}_{2} \mathrm{PO}_{4}$ type. // Ukr. Fiz. Zhurn., 1970, vol. 15, No. 3, p. 460-469 (in Russian).

4. Stasyuk I.V., Levitsky R.R. Dynamical theory of $\mathrm{NH}_{4} \mathrm{H}_{2} \mathrm{PO}_{4}$-type antiferroelectrics with hydrogen bonds. // Izv. Acad. Nauk SSSR, Ser. Fiz., 1971, vol. 35, No. 9, p. 1775-1778 (in Russian).

5. Levitsky R.R., Korinevsky M.A., Stasyuk I.V. A theory of proton ordering in ferroelectrics and antiferroelectrics of orthophosphate type. // Ukr. Fiz. Zhurn., 1974, vol. 19, No. 8, p. 1289-1297 (in Russian).

6. Levitsky R.R., Stasyuk I.V. Approximation of self-consistent field in the de Gennes model. // Ukr. Fiz. Zhurn., 1974, vol. 19, No. 8, p. 1331-1338 (in Russian).

7. Levitsky R.R., Stasyuk I.V., Korynevsky N.A. Dynamics of ferroactive crystals of orthophosphate type. // Ferroelectrics, 1978, vol. 21, p. 481-483.

8. Kozitsky Y.V. Levitsky R.R. Decoupling in the Green function method and sum rules for de Gennes model. // Ukr. Fiz. Zhurn., 1978, vol. 23, No. 4, p. 661-668 (in Russian).

9. Levitsky R.R., Korynevsky N.A., Stasyuk I.V. Distribution function and thermodynamical properties of $\mathrm{KD}_{2} \mathrm{PO}_{4}$ and $\mathrm{ND}_{4} \mathrm{D}_{2} \mathrm{PO}_{4}$ type crystals. // Phys. Stat. Sol. (b), 1978, vol. 88, No. 1, p. 51-63.

10. Kozitsky Y.V. Levitsky R.R., Stasyuk I.V. Polariton states in the orderdisorder type ferroelectrics. // Teor. Mat. Fiz., 1979, vol. 39, No. 1, p. 106-117 (in Russian).

11. Stasyuk I.V., Levitsky R.R., Korinevsky N.A. Collective vibrations of protons in compounds of $\mathrm{KH}_{2} \mathrm{PO}_{4}$ type. // Phys. Stat. Sol. (b), 1979, vol. 91, No. 2, p. $541-550$.

12. Levitskii R.R., Sorokov S.I. Dynamics of a simple model for an antiferroelectrics with order-disorder phase transition. I. Formulation of a diagrammatic method. // Ukr. Fiz. Zhurn., 1979, vol. 24, No. 12, p. 1814-1821 (in Russian). 
13. Levitskii R.R., Sorokov S.I. Dynamics of a simple model for an antiferroelectrics with order-disorder phase transition. II. Correlation functions and polarization waves. // Ukr. Fiz. Zhurn., 1980, vol. 25, No. 1, p. 10-17 (in Russian).

14. Levitskii R.R., Zachek I.R, Varanitskii V.I. Relaxational processes in ferroelectrics with hydrogen bonds of the $\mathrm{KD}_{2} \mathrm{PO}_{4}$ type. // Ukr. Fiz. Zhurn., 1980, vol. 25, No. 11, p. 1961-1969 (in Russian).

15. Korinevsky N.A., Levitskii R.R. Dynamic theory of orthophosphate type in cluster approximation. // Teor. Mat. Fiz., 1980, vol. 42, No. 3, p. 416-429 (in Russian).

16. Stasyuk I.V., Levitsky R.R., Saban A.Ya. Theory of induced by external fields effects and relaxation phenomena in crystals with structural and ferroelectric phase transitions. - In: Problems of Modern Statistical Physics. Kyiv, Naukova Dumka, 1985, p. 274-285 (in Russian).

17. Levitsky R.R., Grigas J., Zachek I.R., Mits Ye.V., Paprotny W. Relaxational dynamics of quasi-one-dimensional $\mathrm{CsD}_{2} \mathrm{PO}_{4}$ type ferroelectrics. // Ferroelectrics, 1986, vol. 67, p. 109-124.

18. Yukhnovskii I.R., Levitskii R.R., Derzhko O.V. Change of critical gas temperature under the influence of resonance irradiation. // Ukr. Fiz. Zhurn., 1988, vol. 33, No. 1, p. 36-38 (in Russian).

19. Yukhnovskii I.R., Kadobyanskii R.M., Levitskii R.R., Derzhko O.V. Effective interactions in groups of identical particles containing excited ones. // Ukr. Fiz. Zhurn., 1989, vol. 34, No. 2, p. 300-307 (in Russian).

20. Yukhnovskii I.R., Levitskii R.R., Derzhko O.V., Novak R.P. Resonance irradiation influence on the gas-liquid phase transition. // Physics Letters A, 1989, vol. 141, p. 18-24.

21. Derzhko O.V., Levitskii R.R., Sorokov S.I. Calculation of correlation functions of spin components taken at different moments of time for the de Gennes onedimensional model. // Ukr. Fiz. Zhurn., 1990, 35, vol. 9, p. 1421-1426 (in Ukrainian).

22. Yukhnovskii I.R., Levitskii R.R., Sorokov S.I., Derzhko O.V. Theory of quasispin systems described by the quasi-one-dimensional Ising model in transverse field with taking into account short-range interactions as a reference system. // Izv. AN SSSR, ser. fiz., 1991, vol. 55, No. 3, p. 481-490 (in Russian).

23. Yukhnovskii I.R., Derzhko O.V., Levitskii R.R. Equilibrium properties of partially excited gas in the cluster expansion method. 1. // Ukr. Fiz. Zhurn., 1992, vol. 37, No. 8, p. 1166-1175 (in Ukrainian). 
24. Yukhnovskii I.R., Derzhko O.V., Levitskii R.R. Equilibrium properties of partially excited gas in the cluster expansion method. 2. // Ukr. Fiz. Zhurn., 1992, vol. 37, No. 9, p. 1354-1362 (in Ukrainian).

25. Yukhnovskii I.R., Derzhko O.V., Levitskii R.R. Cluster expansion method in the theory of equilibrium properties of the gas of atoms of which a part is excited. // Physica A, 1994, vol. 203, p. 381-413.

26. Levitskii R.R., Zachek I.R., Moina A.P. External field influence on phase transition and physical properties of DADP type antiferroelectrics. // Journ. Phys. Studies, 1997, vol. 1, No. 4, p. 575-586 (in Ukrainian).

27. Levitskii R.R., Sokolovskii R.O., Sorokov S.I. Statistical theory for disordered quasi-one-dimensional ferroelectrics with hydrogen bonds. // Condens. Matter Phys., 1997, No. 10, p. 67-92.

28. Levitskii R.R., Sorokov S.I., Sokolovskii R.O. Annealed alloy of Ising magnets within two-site cluster approximation. // Acta Physica Polonica A, 1997, vol. 92 , p. 383-386.

29. Levitskii R.R., Sorokov S.I., Sokolovskii R.O. Quenched Ising model within two-site cluster approximation. // Ferroelectrics, 1997, vol. 192, No. 1-4, p. 1119.

30. Sorokov S.I., Levitskii R.R., Baran O.R. Two-particle cluster approximation for Ising type model with arbitrary value of spin. Correlation functions of Blume-Emery-Griffiths model. // Condens. Matter Phys., 1997, No. 9, p. 5787.

31. Levitskii R.R., Moina A.P. The influence of hydrostatic pressure on DADPtype antiferroelectrics. // Condens. Matter Phys., 1998, vol. 1, No. 2(14), p. $365-382$.

32. Levitskii R.R., Zachek I.R., Sokolovskii R.O. To the theory of relaxation phenomena in quasi-one-dimensional ferroelectrics with hydrogen bonds. Nonequilibrium statistical operator approach. // Condens. Matter Phys., 1998, vol. 1, No. 4(16), p. 849-872.

33. Levitskii R.R., Chernyavskii O.I. Thermodynamics and structural properties of equation of state of two-component partially excited gas mixture. // Collect. Phys. Papers., 1998, vol. 3, p. 327-348 (in Ukrainian).

34. Levitskii R.R., Zachek I.R., Mits Ye.V., Moina A.P. Relaxational phenomena and thermodynamic properties of hydrogen bonded ferroelectrics of orthophospate type. // Collect. Phys. Papers, 1998, vol. 3, p. 417-446 (in Ukrainian). 
35. Levitskii R.R., Sorokov S.I., Baran O.R., Pyndzyn I.M. Thermodynamics of XXZ-model within two-particle cluster approximation. // Journ. Phys. Studies, 1998, vol. 3, p. 257-266 (in Ukrainian).

36. Sorokov S.I., Levitskii R.R., Verkholyak T.M. Effective field method for Ising model with arbitrary ferromagnetic interaction. // Phys. Stat. Sol. (b), 1999, vol. 211, No. 2, p. 759-769.

37. Stasyuk I.V., Levitskii R.R., Moina A.P. External pressure influence on ferroelectrics and antiferroelectrics of the $\mathrm{KH}_{2} \mathrm{PO}_{4}$ family crystals: A unified model. // Phys. Rev. B, 1999, vol. 59, No. 13, p. 8530-8540.

38. Stasyuk I.V., Levitskii R.R., Moina A.P., Zachek I.R., Duda A.S., Romanyuk M.O., Stadnyk V.J., Shcherbina Ye.V. Uniaxial pressure influence on $\mathrm{KH}_{2} \mathrm{PO}_{4}$-type ferroelectrics. // J. Phys. Studies, 1999, vol. 3, No. 4, p. 502512.

39. Levitskii R.R., Sokolovskii R.O. Relaxation dynamics of disordered Ising-like models. // Condens. Matter Phys., 1999, vol. 2, No. 3(19), p. 393-400.

40. Baran O.R., Levitskii R.R. Pair correlation functions of the Ising type model with spin 1 within two-particle cluster approximation. // Phys. stat. sol (b), 2000, vol. 219, p. 357-364.

41. Levitskii R.R., Sorokov S.I., Baran O.R. Reference approach in theory of pseudospin systems. // Condens. Matt. Phys., 2000, vol. 3, No. 3(23) p. 515-543.

42. Stasyuk I.V., Levitskii R.R., Zachek I.R., Moina A.P. The $\mathrm{KD}_{2} \mathrm{PO}_{4}$ ferroelectrics in external fields conjugate to the order parameter: stress $\sigma_{6}$. // Phys. Rev. B, 2000, vol. 62, No. 10, p. 6198-6207.

43. Baran O.R., Levitskii R.R. Re-entrant phase transitions in the Blume-EmeryGriffiths model on a simple cubic lattice. The two-particle cluster approximation // Journ. Phys. Studies, 2001, vol. 5, No. 2, p. 157-161 (in Ukrainian).

44. Levitskii R.R., Lisnii B.M., Baran O.R. Thermodynamics and dielectric properties of $\mathrm{KH}_{2} \mathrm{PO}_{4}, \mathrm{RbH}_{2} \mathrm{PO}_{4}, \mathrm{KH}_{2} \mathrm{AsO} 4, \mathrm{RbH}_{2} \mathrm{AsO} 4$ ferroelectrics. // Condens. Matt. Phys., 2001, vol. 4, No. 3, p. 523-552.

45. Levitskii R.R., Chernyavskii O.I. Equilibrium statistics of two-component partially excited mixture of gases I. Thermodynamic properties. // Ukr. Fiz. Zhurn., 2000, vol. 45, No. 8, p. 998-1008 (in Ukrainian).

46. Stasyuk I.V., Levitskii R.R., Moina A.P., Lisnii B.M. Longitudinal field $\mathrm{KH}_{2} \mathrm{PO}_{4}$ family ferroelectrics. // Ferroelectrics, 2001, vol. 254, p. 213-227.

47. Stasyuk I.V., Levitskii R.R., Zachek I.R., Duda A.S. Influence of $\sigma_{1}-\sigma_{2}$ stress on phase transition and physical properties of $\mathrm{KD}_{2} \mathrm{PO}_{4}$-type ferroelectrics. // Condens. Matter Phys., 2001, vol. 4, No. 3(27), p. 553-578. 
48. Baran O.R., Levitskii R.R. Reentrant phase transitions in the Blume-EmeryGriffiths model on a simple cubic lattice. The two-particle cluster approximation. // Phys. Rev. B, 2002, vol. 65, p. 172407. 